\title{
La fundación de San Luis Tlaxialtemalco
}

\author{
Andrea Martínez Baracs
}

2003

La fundación de San Luis Tlaxialtemalco, según los títulos primordiales de San Gregorio Atlapulco

Delegación Xochimilco-Instituto de Investigaciones

Dr. José María Luis Mora, México.

$\int$ a fundación de San Luis Tlaxialteles de San Gregorio Atlapulco es una edición elaborada a solicitud de San Luis Tlaxialtemalco, pueblo de Xochimilco, en ocasión de cumplirse en el 2003 cuatrocientos años desde su fundación. Con ese fin, Luis Reyes García y Juan Manuel Pérez Zevallos se propusieron reunir y editar los llamados "títulos primordiales" de esa población, dependiente durante el periodo virreinal de la de San Gregorio Atlapulco.

Partían de dos publicaciones. En los Anales de San Gregorio Acapulco, 15201606 (Tlalocan, 1952, vol. III, núm. 2), Byron McAfee y Robert Barlow transcribieron y tradujeron del náhuatl al español los cuatro documentos que integran lo principal de esta edición. El primero, aquí llamado "Título de propiedad del pueblo de San Gregorio Atlapulco (circa 1559)"; el segundo,

ANDREA MARTÍNEZ BARACS: CIESAS.

Desacatos, núm. 14, primavera-verano 2004, pp. 255-258.

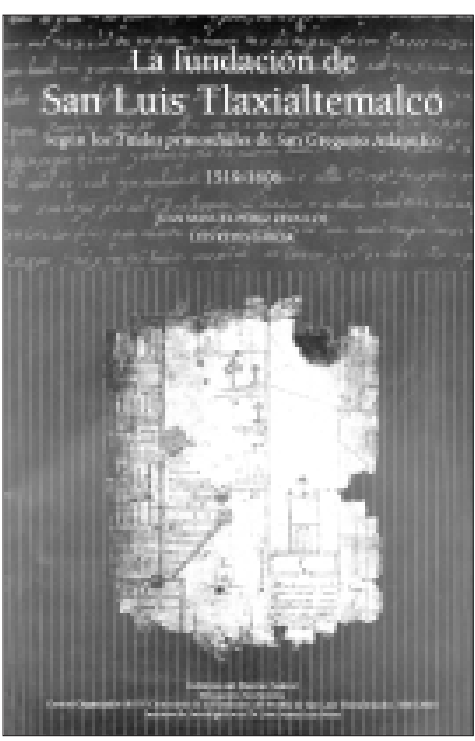

255
"Conflicto por tierras de los naturales de San Luis Tlaxialtemalco con Juan Andrés Meretil, 1595”; el tercero, “Títulos de la congregación de San Gregorio Acapulco, 1693", y el cuarto, "Anales de San Gregorio Atlapulco, 1519-1606”.

La segunda obra que sirvió de base a esta edición es San Gregorio Atlapulco, Xochimilco, D. F. (pueblo que nació 
luchando por sus tierras y ha vivido defendiéndolas, en el IV centenario de su fundación) (1957), edición de Sóstenes N. Chapa del documento en español llamado "Protocolización de títulos del pueblo de San Gregorio Atlapulco (1911)", que es una versión antigua en español de los tres primeros documentos mencionados, seguida de una descripción del cuarto y de dos planos.

Reyes García y Pérez Zevallos lograron encontrar en la Biblioteca Nacional de Antropología e Historia las fotografías que McAfee y Barlow tomaron de los originales que publicaron, salvo las que reproducían el primer documento, que suponemos en esta edición transcrito tal como aparecía en Tlalocan. En el caso de los otros tres documentos, el acceso a las

fotografías de los originales permitió a Luis Reyes García la corrección de transcripción y traducción. El original publicado por Sóstenes Chapa fue hallado por los investigadores en el Archivo General de Notarías, por lo que en la presente edición se ofrece en una nueva transcripción.
A la colección editada originalmente por McAfee y Barlow pertenecían también dos planos hechos según el estilo pictórico indígena, referentes al área de San Gregorio, y una pintura en la que figuran cuatro señores principales y varios glifos toponímicos. Estas tres pictografías son reproducidas en la presente edición, que incluye también fotografías de algunas de las fojas de los documentos, entre ellas cuatro de los Anales, que muestran las representaciones pictóricas de los años nahuas ácatl, técpatl, calli, tochtli.

La traducción libre al español de los tres primeros documentos, que incluye una somera descripción de los Anales y de los dos planos, fue elaborada en 1710, autentificada en 1811 y "protocolizada" en 1911, y es éste el documento que se publica como apéndice en esta edición.

Hasta donde puede deducirse, el "título de propiedad" de San Gregorio fue copiado, en náhuatl pero con muchos errores, primeramente en 1872 , cuando los vecinos de ese pueblo contrataron a un abogado para que se encargara de la defensa legal de sus tierras y ciénega frente a diversos grupos que los pretendían: pueblos vecinos o invasores particulares apoyados por los gobiernos porfiristas. En 1911 se hizo una "copia certificada" de ese título y los dos planos. Hasta donde entendemos, ésa es la versión que McAfee y Barlow fotografiaron. Queda la pregunta: los otros dos documentos de la colección (documentos II y III de esta edición), los anales (doc. III), el plano y la pintura, ¿son originales o copias?

Los cuatro documentos, dos planos y una pintura fueron presentados por San Gregorio para gestionar la recuperación de sus tierras, en el marco de la política de restituciones iniciada en 1915. Su principal lucha era contra el doctor Aureliano Urrutia, quien desde 1903 había ocupado más de 500 hectáreas. En 1914, los pobladores de San Gregorio Atlapulco tomaron con las armas esas tierras; en 1922 el presidente Álvaro Obregón se las restituyó legalmente, pero sólo en 1945 terminó el litigio entre las dos partes, con la victoria definitiva de San Gregorio Atlapulco.

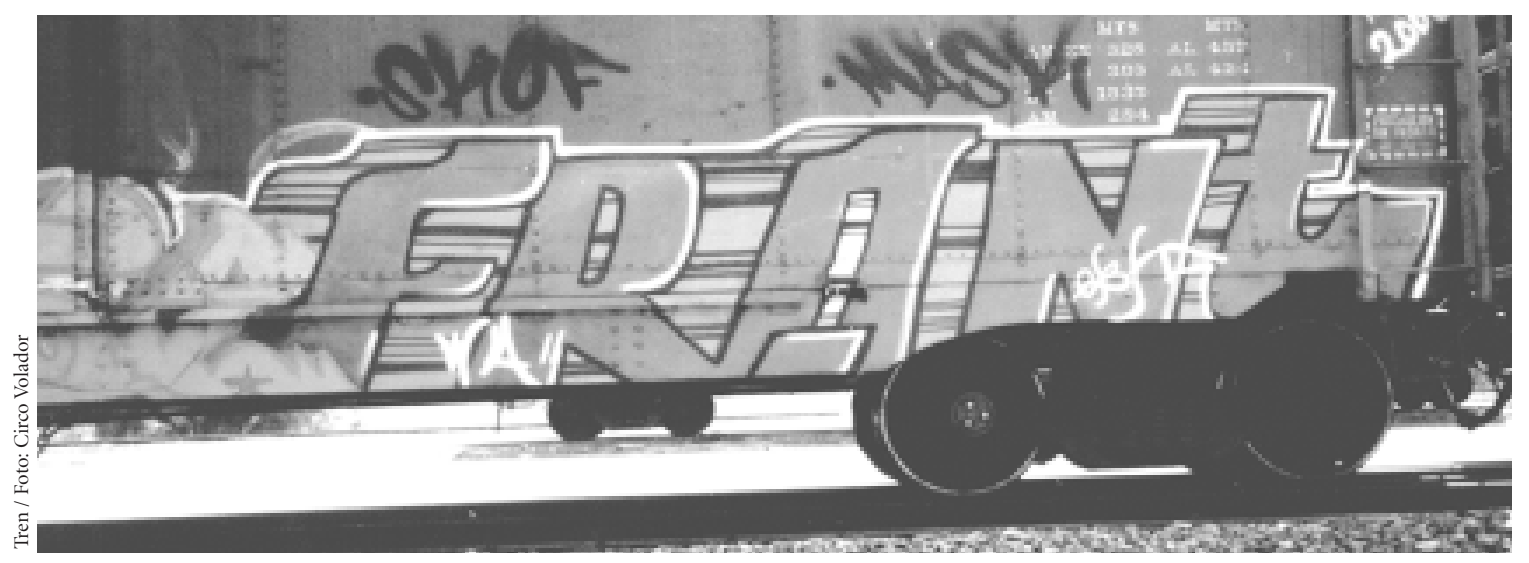




\section{Documento I. “Título de propiedad del pueblo de San Gregorio Atlapulco (circa 1559)"}

En la introducción de la edición, elaborada por Pérez Zevallos, se sitúa a este primer documento como un "título primordial" escrito hacia 1708 , en el periodo en que muchos pueblos de indios produjeron documentos para justificar la posesión de sus tierras frente a la política virreinal de regularización de la propiedad (las "composiciones" de 1692-1754), que amenazaba a los pueblos con legalizar los despojos que habían sufrido. Varios rasgos confirman esta fechación tardía, perceptible ante todo en la índole misma del documento, que reúne episodios sobresalientes de la historia del pueblo en un continuo de hilación épica. Los anales, no las narraciones históricas, fueron el género histórico indígena original, las segundas son en el mundo indígena un producto mestizo y tardío. En cuanto al lenguaje, el hecho de que se trate de una copia tardía impide evaluar con precisión el periodo de su escritura. No obstante, se concluye que se trata de un título realizado o encargado por los vecinos de San Gregorio en el periodo dicho — principios del siglo XVIII-, en el que tal vez incluyeron textos más antiguos y con seguridad su memoria oral, transmitida por los viejos del pueblo: cuentan sus historias en un náhuatl rico que esperemos que algún estudio en el futuro ponga en valor.

Con la retórica de la oratoria mesoamericana, este documento colonial tardío cuenta la historia del pueblo de San Gregorio Atlapulco o Acapul- co, barrio de Xochimilco poseedor de chinampas, que contó con su propia iglesia y sus cuatro merinos o jueces gobernantes durante el periodo colonial. En él se dice, en tono apocalíptico: "cuando llegó el mundo con ello aquí se establecerá [y] si otra vez se destruye el universo, nuevamente vendremos a dar testimonio con la autorización de Dios" (\#23). Contiene al menos un difrasismo del náhuatl clásico, como la referencia a las dependencias como "el ala y la cola". Es un texto épico, escrito en primera persona: "Ya vamos, mis queridos hijos, sobre nuestros linderos, vamos entrando por todas partes, en los cerros de las cuatro partes y en el agua, por órdenes de Dios", y narrativo: "allí conversan, se abrazan, se encuentran..."

El propósito de este documento es declarar la fundación legítima de su pueblo, dentro de un pacto más complejo con el rey de Castilla y sus representantes novohispanos, pacto en el que sobresale desde luego la aceptación de la religión católica. La fundación y la declaración de los linderos se hacen frente a los otros pobladores del área, en particular la propia Xochimilco. La otra finalidad, señalada varias veces, es protegerse de los españoles y llamar a los vecinos a protegerse de ellos: "[rogamos] con las manos cruzadas que nadie dé a los castellanos la tierra, ya que la ganamos por medio de la muerte" (\#23).

Figura Hernán Cortés en persona en 1532 -la presencia de Cortés en ese año no es imposible, pues es precisamente cuando pudo gozar de la posesión de su marquesado - con los viejos fundadores del pueblo, cuyos nombres antiguos y cristianos son claramente señalados: "reciben merced de tierra, agua y cerro. Se ganaron todas las tierras". El pacto inicial con el o los representantes del rey de Castilla incluye la tributación y la adopción de la religión católica: "Entonces dijeron los viejos que ya llegó la fe... que ya vinieron los señores castellanos del rey nuestro señor, para que tributemos, para que paguemos en plata." Implica también el cambio de nombre de los viejos, signo de sometimiento señorial:

Y estaban los viejos, a cada uno de los viejos se les daba cualquier nombre. Y fue cuando vino a llegar el respeto señorial (tlatoccatemahuiztilililiztli) que se corrigió por donde quiera. Sabed vosotros los súbditos ( $y$ atepilhua) que existiréis frente a Dios. Fue cuando bien vino a llegar le humillación señorial (tlatocanepechtequililiztli), allí empezaron a llamarse don Miguel, don Francisco, don Diego, don Juan, don Luis, don Antonio y don Pedro. (\#20)

Si los pactos de origen son importantes, la parte medular del texto es, desde luego, la definición de los linderos del pueblo. La narración nos lleva tramo por tramo, y el recorrido incluye la presencia de los vecinos y su aceptación. Muchos de los linderos están en el agua. Es convocada la gente de las poblaciones grandes y chicas colindantes, mencionadas todas y cada una: "vinieron a ver, les fue tomado juramento, que no sabían de quién era, que ahora es suya, de San Gregorio Acapulco, que es suya la tierra" (\#15).

Otra fecha importante es 1556, año de la construcción de la iglesia, dedicada a San Gregorio: 


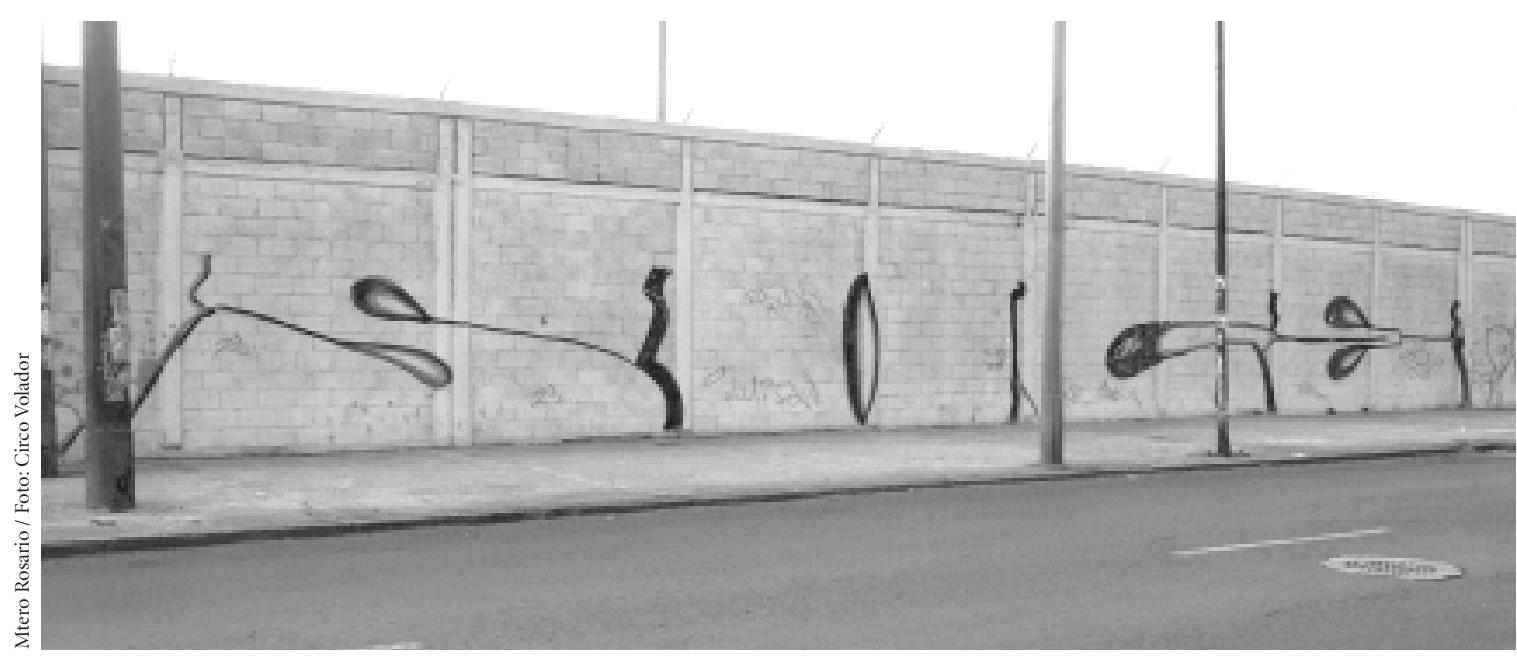

Don Luis de Velasco, (el cual) hizo merced al asentar en su decreto de gobernante cuando los gobernantes dieron el santo San Gregorio, y entonces se establecieron todos los santitos. No estaba ningún castellano cuando se recibió la tierra. Y quien sea tu madre, tu padre, no muestres al castellano lo que dispusieron los viejos. (\#21)

\section{Documento II. Conflicto por tierras de los naturales de San Luis Tlaxialtemalco contra Juan Andrés Meretil, 1595}

Este documento, fechado en 1595 , trata de la intromisión en las tierras de San Luis y San Gregorio de dos "castellanos". El primero fue Juan Andrés Meretil: sus animales dañaron los árboles frutales de los naturales. El pueblo, de acuerdo con el padre guardián del convento franciscano, determinó quemarle su rancho previa protección de sus enseres domésticos: "lejos acarreamos sus bienes para que no se quemaran, justamente enfrente del padre guardián fray Juan
Lozano, para lo cual nos guiamos con una trompeta". El texto relata los sucesos en primera persona y en estilo directo. Respecto al segundo personaje: "Y ahora decimos enfrente al padre guardián que no es a cambio de dinero que te prestamos el cerro de nuestro reverendo padre San Gregorio." Los vecinos y los viejos se opusieron a esta cesión, y el propio colono, al morir, aceptó devolver las tierras "a nuestro querido padre San Gregorio, que lo ha de tomar". La intención del documento parece estar señalada en el pasaje que sigue: los terrenos, "que nadie nunca se los vaya quitando, ningún español. Aquí lo dejamos señalado para nuestros hijos, para que lo sepan, para que nadie se burle de ellos, ningún español”.

\section{Documento III. “Títulos de la congregación de San Gregorio Acapulco, 1603"}

Describe esa congregación, llevada a cabo en 1603: "ahora [son] ya todos los barrios de nuestro padre San Gregorio". Uno de esos barrios, San Luis, fue establecido entonces: "y a los hijos de San Luis les hicieron sus casas".

\section{Documento IV. "Anales de San Gregorio Atlapulco, 1519-1606”}

No se aclara cuándo pudieron ser elaborados. Es un texto breve que casi no contiene referencias a San Gregorio o San Luis. En esta edición fue complementado por numerosas entradas tomadas de otros anales nahuas.

Finalmente, el Apéndice 1 contiene la ya mencionada traducción de 1710 de los cuatro primeros documentos, así como una somera descripción de los planos, incluída en ella originalmente. Los editores añadieron una "relación del convento y asistencia de San Gregorio Atlapulco (1689-169o) tomada del Archivo Franciscano de la Biblioteca Nacional, y un útil mapa de San Luis y San Gregorio. 